\title{
GMR
}

\section{Effects of intra-articular injection of mesenchymal stem cells associated with platelet-rich plasma in a rabbit model of osteoarthritis}

\author{
L.C. Hermeto ${ }^{1}$, R. DeRossi ${ }^{2}$, R.J. Oliveira ${ }^{3,4,5}$, J.R. Pesarini ${ }^{3,4}$, \\ A.C.M.B. Antoniolli-Silva ${ }^{3,4}$, P.H.A. Jardim ${ }^{2}$, A.E. Santana ${ }^{6}$, \\ E. Deffune ${ }^{7}$, J.C. Rinaldi ${ }^{8}$ and L.A. Justulin ${ }^{8}$
}

${ }^{1}$ Programa de Pós-Graduação em Ciências Veterinárias, Faculdade de Medicina Veterinária e Zootecnia, Universidade Federal de Mato Grosso do Sul, Campo Grande, MS, Brasil ${ }^{2}$ Faculdade de Medicina Veterinária e Zootecnia, Universidade Federal de Mato Grosso do Sul, Campo Grande, MS, Brasil ${ }^{3}$ Centro de Estudos em Células Tronco, Terapia Celular e Genética Toxicológica, Hospital Universitário "Maria Aparecida Pedrossian”, Empresa Brasileira de Serviços Hospitalares, Campo Grande, MS, Brasil ${ }^{4}$ Programa de Pós-Graduação em Saúde e Desenvolvimento na Região Centro-Oeste, Faculdade de Medicina, Universidade Federal de Mato Grosso do Sul, Campo Grande, MS, Brasil ${ }^{5}$ Programa de Mestrado em Farmácia, Centro de Ciências Biológicas e da Saúde, Universidade Federal de Mato Grosso do Sul, Campo Grande, MS, Brasil ${ }^{6}$ Departamento de Clínica e Cirurgia Veterinária, Faculdade de Ciências Agrárias e Veterinárias, Universidade Estadual Paulista "Júlio de Mesquita Filho", Jaboticabal, SP, Brasil

${ }^{7}$ Laboratório de Engenharia Celular, Faculdade de Medicina de Botucatu, Universidade Estadual Paulista "Julio de Mesquita Filho", Botucatu, SP, Brasil ${ }^{8}$ Instituto de Biociências, Departamento de Morfologia, Laboratório de Matriz Extra-Celular, Universidade Estadual Paulista "Julio de Mesquita Filho", Botucatu, SP, Brasil

Corresponding author: R.J. Oliveira

E-mail: rodrigo.oliveira@ufms.br

Genetics and Molecular Research 15 (3): gmr.15038569 
Genet. Mol. Res. 15 (3): gmr. 15038569

Received February 19, 2016

Accepted April 15, 2016

Published September 2, 2016

DOI http://dx.doi.org/10.4238/gmr.15038569

Copyright $(C 2016$ The Authors. This is an open-access article distributed under the terms of the Creative Commons Attribution ShareAlike (CC BY-SA) 4.0 License.

ABSTRACT. The current study aims to evaluate the macroscopic and histological effects of autologous mesenchymal stem cells (MSC) and platelet-rich plasma on knee articular cartilage regeneration in an experimental model of osteoarthritis. Twenty-four rabbits were randomly divided into four groups: control group, platelet-rich plasma group, autologous MSC undifferentiated group, and autologous MSC differentiated into chondrocyte group. Collagenase solution was used to induce osteoarthritis, and treatments were applied to each group at 6 weeks following osteoarthritis induction. After 60 days of therapy, the animals were euthanized and the articular surfaces were subjected to macroscopic and histological evaluations. The adipogenic, chondrogenic, and osteogenic differentiation potentials of MSCs were evaluated. Macroscopic and histological examinations revealed improved tissue repair in the MSC-treated groups. However, no difference was found between MSC-differentiated and undifferentiated chondrocytes. We found that MSCs derived from adipose tissue and platelet-rich plasma were associated with beneficial effects in articular cartilage regeneration during experimental osteoarthritis.

Key words: Chondrogenic differentiation; Chondral defect; Arthritis; Cellular therapy

\section{INTRODUCTION}

Osteoarthritis $(\mathrm{OA})$ is a complex disease that causes damage to the articular cartilage and is accompanied by changes in the subchondral bone and the synovium (Findlay, 2010). This disease can arise due to trauma and degenerative diseases and may be age-related. As articular cartilages are limited in their capacity to regenerate, clinical repair of osteoarthritis has proven to be challenging. Currently, new treatment strategies have been developed that aim to enhance the limited self-healing capacity of articular cartilages (Csaki et al., 2008)

The usage of adult mesenchymal stem cells (MSC) in OA treatment is becoming increasingly popular due to the accessibility and abundance of these cells. In addition, they do not involve ethical issues such as those related to the use of embryonic stem cells (Burastero et al., 2010).

MSC are multipotent and non-hemopoietic stem cells; they may be isolated from different sources such as the bone marrow, cord blood, fatty tissue, fetal membranes, amniotic fluid, skeletal muscles, and several other adult tissues (Carrancio et al., 2008). According to

Genetics and Molecular Research 15 (3): gmr.15038569 
Parker and Katz (2006), the most studied MSCs are those derived from bone marrows and adipose tissues. It has been shown that accessibility, processing procedures, and cell yield of MSCs obtained from adipose tissues are comparable to those provided by the bone marrow (Tonchev et al., 2010).

The joint fluid also contains MSCs, but only a limited number of those cells can differentiate into chondrocytes. Furthermore, regenerated cartilage is very fragile, and can be damaged with even a low level of stress to the joints (Gupta et al., 2012). Thus, selfregeneration of cartilage is not only a slow process, but also produces cartilage tissues that are not stable enough to resist intensive use (Uth and Trifonov, 2014). Kim et al. (2015) reported that it is possible to artificially stimulate the regeneration process by delivering MSCs to knee joints affected with OA.

Platelet-rich plasma (PRP) is a simple and effective way to obtain high concentrations of growth factors. This procedure involves separating the platelets from whole blood, and has unique properties for promoting tissue remodeling, wound healing, and angiogenesis (Anitua et al., 2006). PRP intra-articular injection does not act specifically on the cartilage, and may also influence the environment around the joint. Some in vitro studies have shown that PRP and MSCs can act synergistically to promote tissue regeneration (Mishra et al., 2009; Van Pham et al., 2013). The "chemoattractant" property of PRP may lead to recruitment of other cell types that will migrate to damaged tissues, thereby stimulating repair responses (Krüger et al., 2012).

The current study aims to evaluate the association between autologous MSCs (either undifferentiated or differentiated into chondrocytes) and PRP in the regeneration of the knee articular cartilage of rabbits in an experimental model of osteoarthritis.

\section{MATERIAL AND METHODS}

\section{Animals}

Twenty-four adult New Zealand white rabbits weighing $4 \pm 0.5 \mathrm{~kg}$ were used in the current study. The rabbits were kept in individual stalls equipped with burrows and nests in order to minimize distress, and were provided with adequate water and food. The animals were randomized into four groups consisting of six rabbits in each group. All animals were subjected to induced osteoarthritis, and received the following treatments after 6 weeks: GC (control - one saline application), GPRP (PRP - one autologous PRP application), GMSC (undifferentiated MSCs - one autologous PRP + cell application), and GMSCdif (MSCdifferentiated chondrocytes - one autologous PRP + cell application). The experimental protocol was approved by the Ethics Committee on animal use (CEUA) of UNESP, under No. $027839 / 12$. Experiments were conducted in accordance to the ethical principles adopted by the Brazilian College of Animal Experimentation (COBEA). Measures were taken to minimize distress to the animals.

\section{Induction of experimental osteoarthritis}

The rabbits were anesthetized by intramuscular administration of $30 \mathrm{mg} / \mathrm{kg}$ ketamine (Vetanarcol, König, São Paulo, Brazil) and $5 \mathrm{mg} / \mathrm{kg}$ xylazine (Kensol, König). Collagenase (Collagenase Type II-Clostridium histolyticum; Gibco Life Technologies, USA) solution (0.5 $\mathrm{mL} 2 \mathrm{mg}$ collagenase $/ 0.5 \mathrm{~mL}$ sterile PBS) was intra-articularly injected into the right knee

Genetics and Molecular Research 15 (3): gmr.15038569 
joint under aseptic conditions. The injection was given twice, on day 1 and day 4, according to the methods described by Kikuchi et al. (1998). At the end of anesthetic recovery, the animals were kept in their stalls, and were allowed free movements.

\section{Platelet-rich plasma protocol}

PRP was prepared using two centrifugation techniques, as previously described by Vendramin et al. (2006). Whole blood $(10 \mathrm{~mL})$ was drawn from each rabbit using sterile syringes filled with $10 \%$ sodium citrate. An aliquot of blood was obtained to determine the platelet count; the rest of the blood was then centrifuged at $300 \mathrm{~g}$ for $10 \mathrm{~min}$ at room temperature. Plasma was transferred to new sterile tubes to be further centrifuged at $640 \mathrm{~g}$ for $10 \mathrm{~min}$. Two-thirds of the supernatant plasma was discarded, and the remaining (approximately $0.5 \mathrm{~mL}$ ) plasma and precipitated platelets were designated as PRP. At the time of application, PRP injections were supplemented with $0.05 \mathrm{~mL} 10 \%$ calcium gluconate. Platelet counts were also performed on PRP samples.

\section{Adipose tissue harvesting and MSC isolation and culture}

The rabbits were anesthetized with intramuscular administration of $30 \mathrm{mg} / \mathrm{kg}$ ketamine and $5 \mathrm{mg} / \mathrm{kg}$ xylazine prior to tissue harvesting. Infiltrative anesthesia was performed by applying lidocaine between the scapulae, at $7 \mathrm{mg} / \mathrm{kg}$, under aseptic conditions. After $3 \mathrm{~min}$, a $1.0-$ to $2.0-\mathrm{cm}$ incision was made between the scapulae, and the adipose tissue was removed from the subcutaneous space by divulsion; the incision was then closed with nylon sutures. The harvested adipose tissue was washed three to four times with PBS and suspended in collagenase solution ( $2 \mathrm{mg}$ collagenase/mL HEPES medium), at $2 \mathrm{~mL}$ solution/g adipose tissue. It was cultured overnight at $37^{\circ} \mathrm{C}$ with $5 \% \mathrm{CO}_{2}$. Enzyme activity was then neutralized with Knockout DMEM (knockout Dulbecco's modified Eagle's medium - Gibco Life Technologies) containing 10\% fetal bovine serum (Gibco Life Technologies). The infranatant was centrifuged at $300 \mathrm{~g}$ for $10 \mathrm{~min}$ at room temperature in order to pellet the cells. Cells were filtered to remove debris, and seeded on tissue culture plates for further expansion. Cell cultures were kept in Knockout DMEM supplemented with 10\% FBS and antibioticantimycotic solution at $37^{\circ} \mathrm{C}$ with $5 \% \mathrm{CO}_{2}$. The culture medium was changed every 2 days. After reaching approximately $80 \%$ confluence, the cells were trypsinized ( $0.025 \%$ trypsin) and plated at a density of $5000 \mathrm{cell} / \mathrm{s} / \mathrm{cm}^{2}$; this procedure was repeated each time when cell confluence reached $80 \%$. After two passages, the cells were ready to be administered; cells were injected immediately following trypsinization. Two flasks of cells were divided into two sterile tubes for adipogenic and osteogenic differentiation. Cells from the GMSC group were counted, suspended in autologous PRP, and intra-articularly injected into the right knee joint under aseptic conditions ( $4 \times 10^{6}$ cells). The GMSCdif cells $\left(4 \times 10^{6}\right.$ per animal) were first differentiated into chondrocytes.

\section{Chondrogenic differentiation}

Chondrogenic differentiation was performed as a three-dimensional pellet culture. Cells were kept for $24 \mathrm{~h}$ in DMEM medium in sterile $15-\mathrm{mL}$ conical tubes at $1 \mathrm{x} 10^{6} \mathrm{cells} / \mathrm{cm}^{2}$. The replacement medium was obtained from the STEMPRO Chondrogenesis Differentiation

Genetics and Molecular Research 15 (3): gmr.15038569 
Kit (Gibco Life Technologies), and the cells were kept in culture for 21 days. The medium was changed every 3 days. After the culture period, the cells were suspended in autologous PRP, and intra-articularly injected into the right knee joint under aseptic conditions. Four aliquots were prepared for histological evaluations. Two control flasks were kept in Knockout DMEM supplemented with $10 \% \mathrm{FBS}$ and antibiotics. Two other flasks were kept in solution contained in the STEMPRO Chondrogenesis Differentiation Kit. The pellets were subjected to routine histological processing, and were then stained by toluidine blue (T\&B).

\section{Adipogenic and osteogenic differentiation}

Cells were seeded onto four plates at a density of $2 \times 10^{5}$ cells $/ \mathrm{cm}^{2}$ (Urt-Filho et al., 2016). Two control plates were kept in Knockout DMEM supplemented with $10 \%$ FBS and antibiotics. The cells were kept for $24 \mathrm{~h}$ in DMEM, as described above. The medium was then replaced with that from the STEMPRO Adipogenic and Osteogenesis Differentiation Kit (Gibco Life Technologies). The cultures were maintained for 14 days, and medium was changed every 3 days. After the culturing period, the cells were fixed with $4 \%$ paraformaldehyde for 1 h. Adipogenic differentiation was confirmed by Oil Red O staining. Osteogenic differentiation was confirmed by Alizarin Red staining.

\section{Macroscopic evaluation}

After 60 days of intra-articular applications, the animals were euthanized via a thiopental overdose, followed by potassium chloride. The distal femur was immediately dissected and collected, and the trochlear groove, as well as the medial and lateral condyles, were selected for macroscopic score evaluation. The gross appearance of the articular surface was blindly scored, following the criteria set by Yoshimi et al. (1994). This system assigns scores from 0 to 5 (normal, smooth aspect; irregularities; fibrillation; erosion; full-thickness erosion and fissuring at the subchondral bone; cartilage loss).

\section{Histological examinations}

Following macroscopic evaluation, the distal femur was fixed with $10 \%$ neutral buffered formalin, $\mathrm{pH} 7.4$, and decalcified with 10\% EDTA. The lateral and medial sides of the femoral condyle were selected and embedded in paraffin. Tissue micro-sections $(5 \mathrm{~mm})$ were prepared and stained with hematoxylin and eosin (H\&E) as well as with T\&B. The cartilage regions were blindly scored by the evaluator, using the scoring system described by Mankin et al. (1971), with modifications. The histological score represented the sum of four parameters: articular cartilage structure (0-6), cellularity (0-3), Toluidine blue staining (0-4), and tidemark integrity $(0-1)$. This modified Mankin score had a maximum score of 14 and a minimum score of 0 (completely normal cartilage).

\section{Statistical analysis}

The histological and macroscopic scores were analyzed using the Kruskal-Wallis test, followed by the Dunn test. Differences were considered to be significant when $\mathrm{P}<0.05$. Descriptive statistics were applied to data from the platelet counts.

Genetics and Molecular Research 15 (3): gmr.15038569 


\section{RESULTS}

\section{Chondrogenic differentiation}

Figure 1 shows T\&B staining of the cell pellets used for chondrogenic differentiation and the control. It was not possible to see the matrix in the control pellets, only isolated cells. However, we observed intense extracellular matrix production in the differentiated pellets.

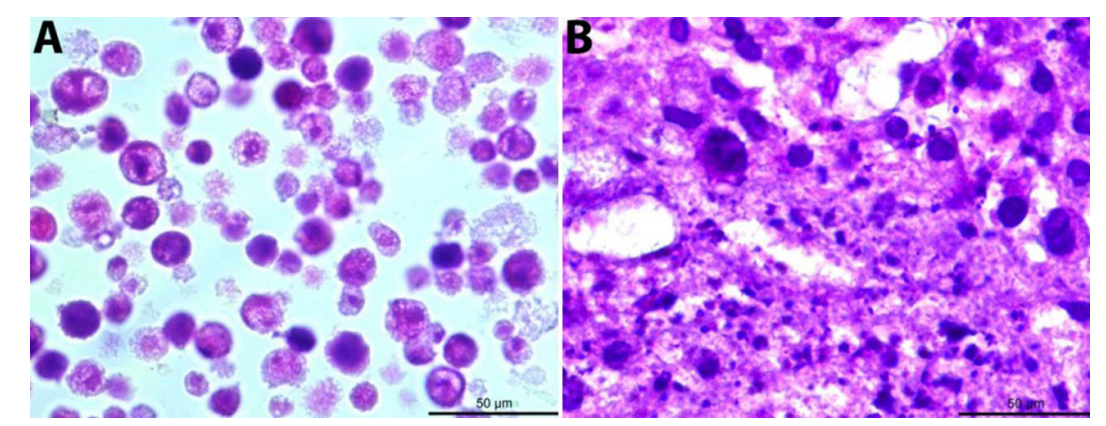

Figure 1. Chondrogenic differentiation - T\&B. A. Control cells (Knockout DMEM culture). B. Differentiated cells (medium for chondrogenic differentiation) with intense extracellular matrix production (100X magnification).

\section{Adipogenic and osteogenic differentiation}

The adipogenic and osteogenic differentiation protocols were confirmed by morphological changes typical of these cell types. Control cells were plastic-adherent, and showed the typical spindle-shaped, fibroblast-like morphology (Figure 2A and C). As illustrated by Figure 2B, cells exhibited the typical intracellular, red-stained lipid vacuoles (arrow), which was validated by Oil Red O staining. As shown by Figure 2D, Alizarin Red staining of calcium deposit in the extracellular matrix confirmed osteogenic differentiation (arrows).

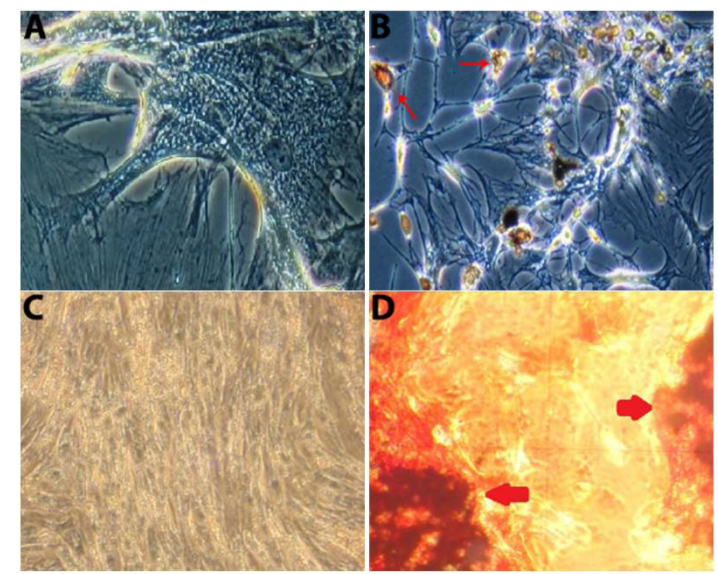

Figure 2. Morphological changes induced in adipogenic and osteogenic differentiation of mesenchymal stem cells. Cultures of adherent stem cells (A and $\mathbf{C}$ ), adipogenic differentiation (B), osteogenic differentiation (arrows, D) (20X magnification). 


\section{Assessing the prepared PRP}

The mean number of counted platelets in the peripheral blood was $287.16 \pm 8.89 / \mu \mathrm{L}$. The mean PRP platelet count was $997.42 \pm 48.01 / \mu \mathrm{L}$; the concentration of platelets in PRP was three times that of whole blood.

\section{Macroscopic evaluation}

Significant differences were found between stem cell-treated and -untreated groups. Means \pm SD macroscopic scores were as follows: GC: $2.5 \pm 0.5477$; GPRP: $2.5 \pm 0.5477$; GMSC: $1 \pm 0.8944$; GMSCdif: $0.833 \pm 0.4082(\mathrm{P}<0.0001$; Figure 3$)$.

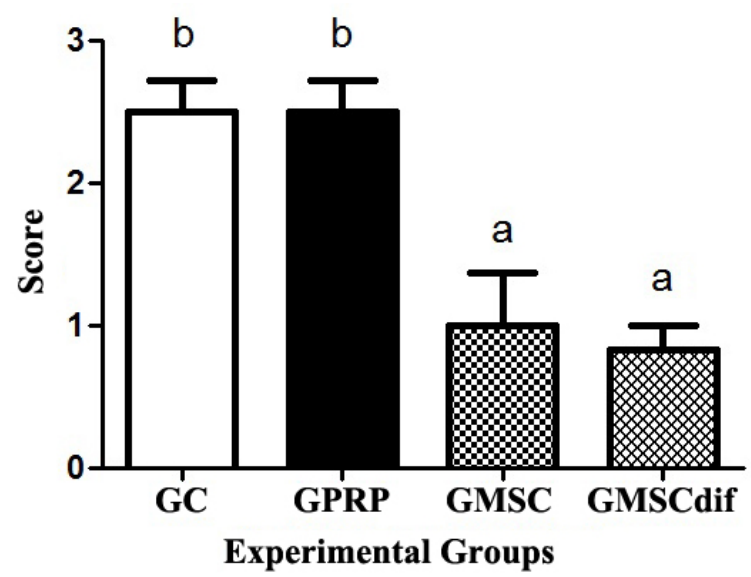

Figure 3. Macroscopic evaluation. Scores (means $\pm \mathrm{SD}$ ) are calculated using the criteria set by Yoshimi et al. (1994). Non-parametric tests (Kruskal-Wallis followed by Dunn's tests) were used to evaluate the statistical significance of the results $(\mathrm{P}<0.0001)$.

The articular cartilage showed reduction in the severity of lesions in the GMSC and GMSCdif groups (Figure 4, sections A-D). Two animals from the GMSC group and one from the GMSCdif group showed normal articular cartilage, which exhibited a while glossy appearance with no noticeable evidence of macroscopic degeneration (Figure 4, sections A and $\mathrm{B}$ ). In the GC and GPRP groups, gross OA features, including fibrillation and erosion, were observed (Figure 4, sections E-I).

\section{Histological examination}

The MSC-treated groups showed improved regeneration as compared to the GC and GPRP groups (Figure 5). The means \pm SD histological scores were as follows: GC: $6.5 \pm 1.22$; GPRP: $6.16 \pm 0.98$; GMSC: $2.83 \pm 0.408$, and GMSCdif: $3.16 \pm 0.75$. Significant differences were found between the MSC-treated groups $v s$ the GC and GPRP groups $(\mathrm{P}=0.0003)$. No significant differences were observed between the GMSC and GMSCdif groups and between the GC and GPRP groups. 


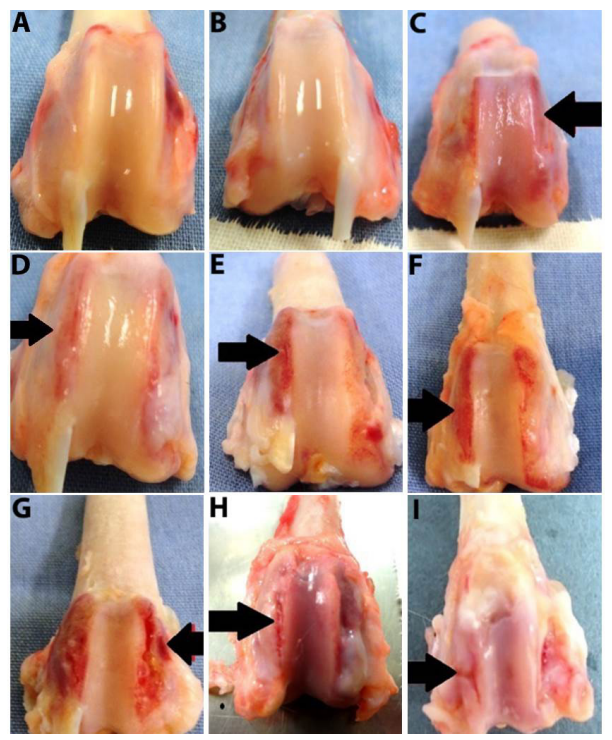

Figure 4. Macroscopic evaluation. A. and B. Smooth and shiny surface (GMSC and GMSCdif groups); C. and D. slight surface irregularities (arrow; GMSC and GMSCdif group); E. and F. thickness defects and fibrillation (arrow; GPRP group); G. H. I. erosion (arrow; GC group).

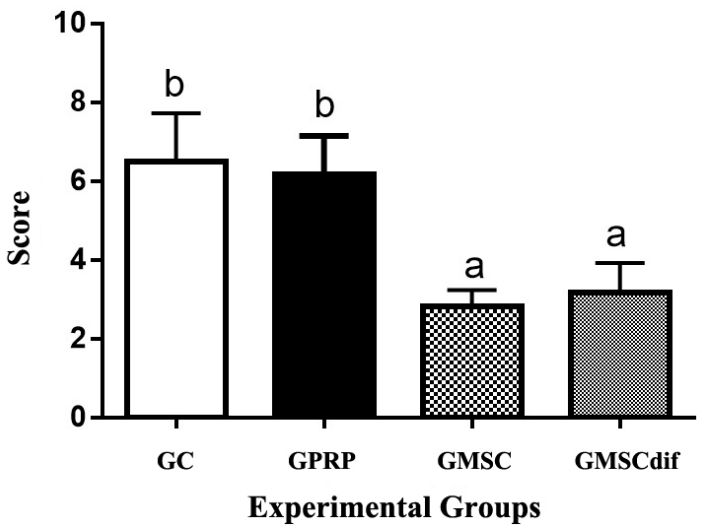

Figure 5. Histological evaluation. Scores (means \pm SD) are calculated according to methods developed by Mankin et al. (1971). Non-parametric tests (Kruskal-Wallis followed by the Dunn test) were used to evaluate the statistical significance of the results $(\mathrm{P}=0.0003)$.

The most severe cases of degeneration were observed in the GC and GPRP groups. Structural disorganization, severe hypocellularity of chondrocytes, and deep fissures were observed. In addition, in some areas, there was a loss of superficial and deep layers, which led to exposure of the calcified zone. In comparison, the injuries in the MSC-treated groups were more superficial, with small irregular areas on the surface layer. The MSC-treated groups showed cartilage tissue with mild surface irregularity, diffuse hypercellularity, and clustering (Figure 6). 

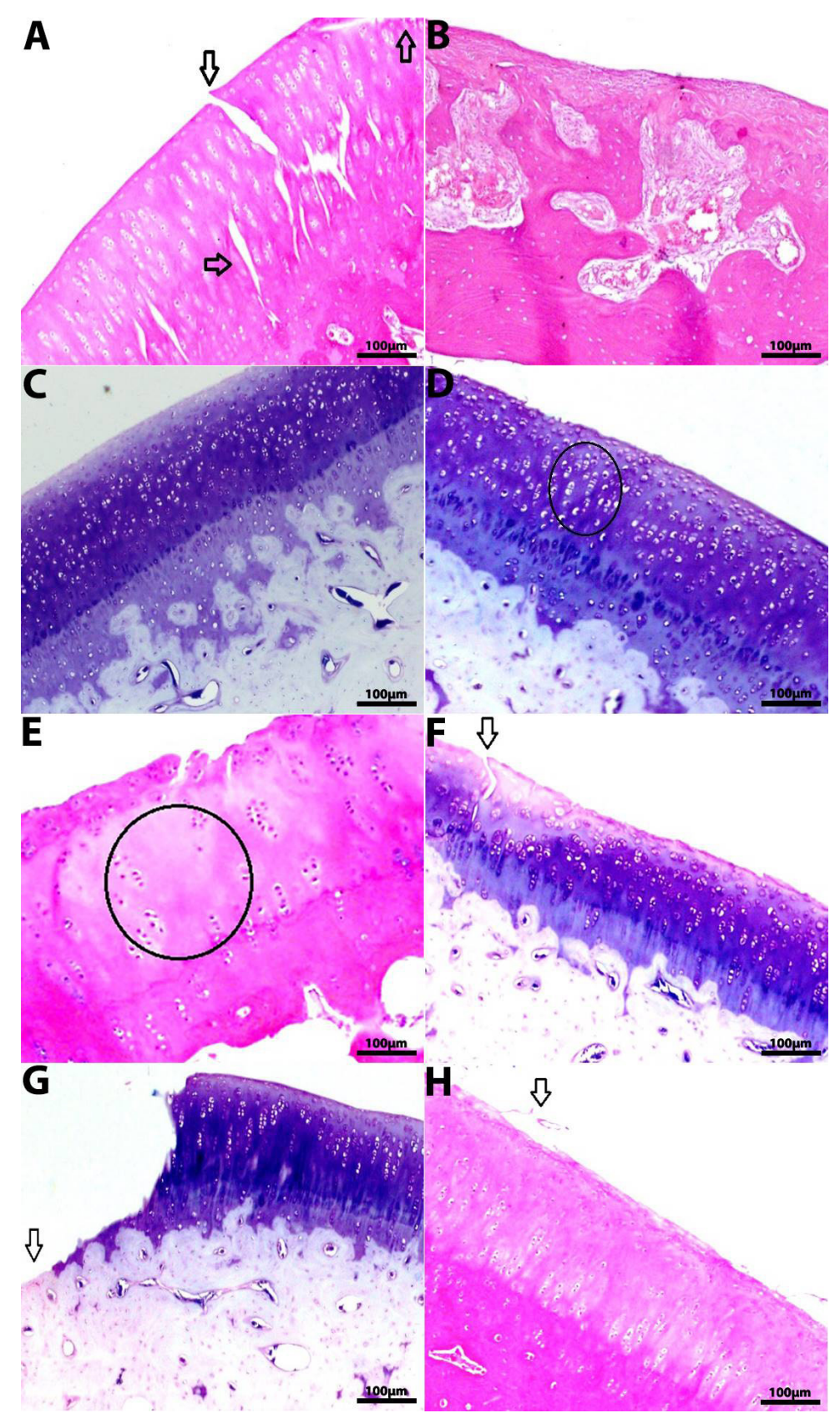

Figure 6. Histological evaluation. A. Clefts in superficial, transitional, and deep zones (arrows) (GPRP group - H\&E); B. structural disorganization (GC group - H\&E); C. diffuse hypercellularity (GMSC group - T\&B); D. clustering of chondrocytes (ellipse) (GMSCdif group - T\&B); E. hypocellularity of chondrocytes (ellipse) (GPRP group - H\&E); F. mild surface irregularities and clefts in the superficial zones (arrow) (GMSC group - T\&B); G. Loss of superficial and deep layers, and consequent exposure of the calcified zone (GC group - T\&B); H. mild surface irregularities (GMSCdif group - H\&E).

Genetics and Molecular Research 15 (3): gmr.15038569 


\section{DISCUSSION}

$\mathrm{OA}$ is the most common clinical syndrome of joint pain and dysfunction and results in functional limitation and reduced quality of life. This disease is progressive and leads to irreversible loss of the cartilage layer (Goldring and Goldring, 2007). Currently, pharmacological therapies for this disease can only achieve palliation of pain and discomfort (Csaki et al., 2008). Therefore, there is an urgent need for the development of alternative therapies that can fundamentally prevent the destruction of cartilages or stimulate its repair (Yun et al., 2016). In the present study, we investigated the effect of PRP and MSC in the treatment of OA. The ideal treatment for OA should aim to block cartilage catabolism, and enhance the regeneration of normal cartilage. The main goal of using MSC for OA treatment is to support the self-healing process of joint cartilage, which results in relief from OA symptoms (Davatchi et al., 2011).

The lapine model has been widely used in cartilage regeneration research (Chu et al., 2010). However, although this is a practical animal model, rabbits have relatively thin cartilages (Räsänen and Messner, 1996). Rabbits were still a suitable model for the current study, since early stages of osteoarthritis were evaluated without performing chondral defects, and the thin cartilage of these animals was not an impediment to the procedures employed in the study.

The application of intra-articular collagenase was successfully performed in all animals, and they recovered from anesthesia without complications or changes to normal behaviors. This method is less invasive as compared to experimental surgical methods; it caused less stress to animals since the induction period only lasted for 4 weeks (Kikuchi et al., 1998). Conventional methods for ligaments and meniscus rupture require approximately 8 to 12 weeks to reach the expected degeneration, and can cause additional discomfort to the animals (Kamekura et al., 2005).

The adipose tissue was chosen as the source of MSCs, since it offered greater MSC yield in comparison to other tissues such as the bone marrow (Busser et al., 2014). In addition, it was an easier location for collecting cells. Estes et al. (2010) stated that MSCs derived from adipose tissues have higher chondrogenic differentiation potential. We confirmed MSC plasticity via adipogenic, osteogenic, and chondrogenic differentiation, according to the protocol outlined by Pittenger et al. (1999).

The protocol for obtaining PRP was satisfactory, and according to Whitlow et al. (2008), the concentration of platelets obtained in the PRP is three to five times higher than that in whole blood. However, the experimental group treated with PRP only did not show clinical improvements. It is important to highlight that the current study aimed to use PRP as a vehicle for MSC application, and studies have found that multiple and sequential applications are required to obtain improvements in OA and chondral defects when using PRP alone (Khoshbin et al., 2013). Recent investigations have shown that growth factors found in the PRP function as carriers, and may enhance, stimulate, or even extend the effects of MSCs (Vilar et al., 2013). Factors such as TGF- $\beta 1$, FGF, and PDGF were found to promote chondrogenesis and were also shown to be chondroprotective (Lee et al., 2010).

In our study, MSC-treated groups showed improved macroscopic changes on the articular surface as compared to other treatment groups, similar to results reported by Grigolo et al. (2009), Desando et al. (2013) and Singh et al. (2014).

Liu et al. (2014) studied human acellular amniotic membrane loaded with bone marrow mesenchymal stem cells in repair of the articular cartilage defect in rabbits. The

Genetics and Molecular Research 15 (3): gmr.15038569 
authors showed that treated cartilage displayed improved results as compared to the control group, suggesting that MSCs play a dominant role in cartilage defect repair.

Histological examinations in our study showed that the MSC-treated groups yielded higher scores, similar to results obtained by Mokbel et al. (2011). It was reported that intralesional MSC implants lead to increased number of progenitor cells in the tissue, which in turn increases the regenerative potential of the injured tissue, and can promote cell differentiation. Similarly, Grigolo et al. (2009), Desando et al. (2013), and Singh et al. (2014) also confirmed that MSC-treated groups are associated with higher histological scores.

In a previous study, Yun et al. (2016) investigated the clinical effects of PRP and MSC in experimental OA, and concluded that combination therapy using both cells has beneficial and synergistic effects on OA via articular extracellular matrix synthesis, chondrocyte proliferation, and anti-inflammatory responses. It was concluded that combination treatment of MSC and PRP may be very useful as an inflammatory regulator for treatment of OA.

In our study, no difference was observed between groups that were treated with MSCdifferentiated chondrocytes and those that were not. It is possible that the cells were able to interact with the microenvironment of the joint, and undergo chondrogenic differentiation without in vitro differentiation. MSC chondrogenesis may be triggered by the extracellular matrix, growth factors, and by the inductor media. It was suggested that MSCs need to be differentiated into chondrocytes inside the intra-articular environment for therapeutic effectiveness (Chen et al., 2009). In support of our results, other studies have stated that MSCs are able to differentiate into specific cell types depending on the environment they reside in. The interactions between MSCs and the extracellular matrix may be a key factor for its differentiation into chondrocytes (Djouad et al., 2007). The OA microenvironment may affect MSC's ability to regenerate the articular cartilage matrix or the subchondral bone. This effect can be regulated by different signaling factors secreted by the resident chondrocytes or osteoblasts (Birmingham et al., 2012). In vivo MSC differentiation is triggered by the interactions between signaling molecules emitted by local and neighboring cells, which are transduced via extracellular or intracellular pathways associated with MSC membrane receptors, cytokines and soluble growth factors, extracellular matrix proteins such as collagen and proteoglycans, or by direct interactions with resident chondrocytes (Leyh et al., 2014). Furthermore, Van Pham et al. (2013) stated that PRP not only stimulates MSC proliferation, but can also induce its differentiation into chondrogenic cells. MSCs treated with PRP exhibited upregulated expression of chondrogenesis-related gene such as col-II, Sox9, and aggrecan. Furthermore, studies have shown that expression of col-II was increased in PRP groups as compared with the controls. Therefore, it is possible that PRP is an important factor that promotes both in vitro and in vivo chondrogenesis of MSCs. As a result, there is a need to differentiate MSCs prior to therapeutic application.

Although cartilage regeneration using MSCs may be a promising avenue that offers a minimally invasive and nonsurgical alternative to conventional therapies, many issues need to be investigated prior to broad application of this treatment. The main mechanism of action for this regenerative behavior remains unclear. Cai et al. (2007) suggested that this enhanced regenerative ability may be due to the secretory effects of the injected stem cells. Ong et al. (2013) stated that enhanced regeneration may be due to direct engraftment and differentiation of stem cells that were introduced into the diseased joints; Pak et al. (2016) postulated that it could be due the combination of secretory effects and direct engraftment of stem cells. These authors analyzed the clinical data of patients that received MSCs with PRP, and have

Genetics and Molecular Research 15 (3): gmr.15038569 
concluded that it can be an effective treatment.

In conclusion, a combination therapy using MSCs and PRP is beneficial in the current experimental model of osteoarthritis. No difference was found in the macroscopic and histological structures between using undifferentiated MSCs and MSC-differentiated chondrocytes. The results from this study have provided the basis for further investigation in other animal models and clinical trials and have highlighted the potential of MSCs and PRPs in regenerative medicine.

\section{Conflicts of interest}

The authors declare no conflict of interest.

\section{ACKNOWLEDGMENTS}

We thank CAPES for the Post-doctoral scholarship to L.C. Hermeto.

\section{REFERENCES}

Anitua E, Sánchez M, Nurden AT, Nurden P, et al. (2006). New insights into and novel for platelet-rich fibrin therapies. Trends Biotechnol. 24: 227-234. http://dx.doi.org/10.1016/j.tibtech.2006.02.010

Birmingham E, Niebur GL, McHugh PE, Shaw G, et al. (2012). Osteogenic differentiation of mesenchymal stem cells is regulated by osteocyte and osteoblast cells in a simplified bone niche. Eur. Cells Mater. 12: 13-27.

Burastero G, Scarfi S, Ferraris C, Fresia C, et al. (2010). The association of human mesenchymal stem cells with BMP-7 improves bone regeneration of critical-size segmental bone defects in athymic rats. Bone 47: 117-126. http://dx.doi. org/10.1016/j.bone.2010.03.023

Busser H, De Bruyn C, Urbain F, Najar M, et al. (2014). Isolation of adipose-derived stromal cells without enzymatic treatment: expansion, phenotypical, and functional characterization. Stem Cells Dev. 23: 2390-2400. http://dx.doi. org $/ 10.1089 / \mathrm{scd} .2014 .0071$

Cai L, Johnstone BH, Cook TG, Liang Z, et al. (2007). Suppression of hepatocyte growth factor production impairs the ability of adipose-derived stem cells to promote ischemic tissue revascularization. Stem Cells 25: 3234-3243. http:// dx.doi.org/10.1634/stemcells.2007-0388

Carrancio S, López-Holgado N, Sánchez-Guijo FM, Villarón E, et al. (2008). Optimization of mesenchymal stem cell expansion procedures by cell separation and culture conditions modification. Exp. Hematol. 36: 1014-1021. http:// dx.doi.org/10.1016/j.exphem.2008.03.012

Chen WH, Liu HY, Lo WC, Wu SC, et al. (2009). Intervertebral disc regeneration in an ex vivo culture system using mesenchymal stem cells and platelet-rich plasma. Biomaterials 30: 5523-5533. http://dx.doi.org/10.1016/j. biomaterials.2009.07.019

Chu CD, Szczodry M and Bruno S (2010). Animal models for cartilage regeneration and repair. Tissue Eng. Part B Rev. 16: 105-115. http://dx.doi.org/10.1089/ten.teb.2009.0452

Csaki C, Schneider PR and Shakibaei M (2008). Mesenchymal stem cells as a potential pool for cartilage tissue engineering. Ann. Anat. 190: 395-412.http://dx.doi.org/10.1016/j.aanat.2008.07.007

Davatchi F, Abdollahi BS, Mohyeddin M, Shahram F, et al. (2011). Mesenchymal stem cell therapy for knee osteoarthritis. Preliminary report of four patients. Int. J. Rheum. Dis. 14: 211-215. http://dx.doi.org/10.1111/j.1756185X.2011.01599.X

Desando G, Cavallo C, Sartoni F, Martini L, et al. (2013). Intra-articular delivery of adipose derived stromal cells attenuates osteoarthritis progression in an experimental rabbit model. Arthritis Res. Ther. 15: R22.http://dx.doi.org/10.1186/ar4156

Djouad F, Delorme B, Maurice M, Bony C, et al. (2007). Microenvironmental changes during differentiation of mesenchymal stem cells towards chondrocytes. Arthritis Res. Ther. 9: R33.http://dx.doi.org/10.1186/ar2153

Estes BT, Diekman BO, Gimble JM and Guilak F (2010). Isolation of adipose-derived stem cells and their induction to a chondrogenic phenotype. Nat. Protoc. 5: 1294-1311. http://dx.doi.org/10.1038/nprot.2010.81

Findlay DM (2010). If good things come from above, do bad things come from below? Arthritis Res. Ther. 12: 119. http:// dx.doi.org/10.1186/ar3007

Genetics and Molecular Research 15 (3): gmr.15038569 
Goldring MB and Goldring SR (2007). Osteoarthritis. J. Cell. Physiol. 213: 626-634. http://dx.doi.org/10.1002/jcp.21258 Grigolo B, Lisignoli G, Desando G, Cavallo C, et al. (2009). Osteoarthritis treated with mesenchymal stem cells on hyaluronan-based scaffold in rabbit. Tissue Eng. Part C. Methods 15: 647-658. http://dx.doi.org/10.1089/ten. tec.2008.0569

Gupta PK, Das AK, Chullikana A and Majumdar AS. (2012). Mesenchymal stem cells for cartilage repair in osteoarthritis. Stem Cell Res. Ther. 3: 25. http://dx.doi.org/10.1186/scrt116

Kamekura S, Hoshi K, Shimoaka T, Chung U, et al. (2005). Osteoarthritis development in novel experimental mouse models induced by knee joint instability. Osteoarthr. Cartil. 13: 632-641.http://dx.doi.org/10.1016/j.joca.2005.03.004

Khoshbin A, Leroux T, Wasserstein D, Marks P, et al. (2013). The efficacy of platelet-rich plasma in the treatment of symptomatic knee osteoarthritis: a systematic review with quantitative synthesis. Arthroscopy 29: 2037-2048. http:// dx.doi.org/10.1016/j.arthro.2013.09.006

Kikuchi T, Sakuta T and Yamaguchi T (1998). Intra-articular injection of collagenase induces experimental osteoarthritis in mature rabbits. Osteoarthr. Cartil. 6: 177-186.http://dx.doi.org/10.1053/joca.1998.0110

Kim YS, Kwon OR, Choi YJ, Suh DS, et al. (2015). Comparative matched-pair analysis of the injection versus implantation of mesenchymal stem cells for knee osteoarthritis. Am. J. Sports Med. 43: 2738-2746. http://dx.doi. org $/ 10.1177 / 0363546515599632$

Krüger JP, Hondke S, Endres M, Pruss A, et al. (2012). Human platelet-rich plasma stimulates migration and chondrogenic differentiation of human subchondral progenitor cells. J. Orthop. Res. 30: 845-852. http://dx.doi.org/10.1002/ jor.22005

Lee CH, Cook JL, Mendelson A, Moioli EK, et al. (2010). Regeneration of the articular surface of the rabbit synovial joint by cell homing: a proof of concept study. Lancet 376: 440-448. http://dx.doi.org/10.1016/S0140-6736(10)60668-X

Leyh M, Seitz A, Dürselen L, Schaumburger J, et al. (2014). Subchondral bone influences chondrogenic differentiation and collagen production of human bone marrow-derived mesenchymal stem cells and articular chondrocytes. Arthritis Res. Ther: 16: 453.http://dx.doi.org/10.1186/s13075-014-0453-9

Liu PF, Guo L, Zhao DW, Zhang ZJ, et al. (2014). Study of human acellular amniotic membrane loading bone marrow mesenchymal stem cells in repair of articular cartilage defect in rabbits. Genet. Mol. Res. 13: 7992-8001. http:// dx.doi.org/10.4238/2014.September.29.12

Mankin HJ, Dorfman H, Lippiello L and Zarins A (1971). Biochemical and metabolic abnormalities in articular cartilage from osteo-arthritic human hips. II. Correlation of morphology with biochemical and metabolic data. J. Bone Joint Surg. Am. 53: 523-537.

Mishra A, Tummala P, King A, Lee B, et al. (2009). Buffered platelet-rich plasma enhances mesenchymal stem cell proliferation and chondrogenic differentiation. Tissue Eng. Part C Methods 15: 431-435. http://dx.doi.org/10.1089/ ten.tec.2008.0534

Mokbel A, El-Tookhy O, Shamaa AA, Sabry D, et al. (2011). Homing and efficacy of intra-articular injection of autologous mesenchymal stem cells in experimental chondral defects in dogs. Clin. Exp. Rheumatol. 29: 275-284.

Ong E, Chimutengwende-Gordon M and Khan W (2013). Stem cell therapy for knee ligament, articular cartilage and meniscal injuries. Curr. Stem Cell Res. Ther. 8: 422-428. http://dx.doi.org/10.2174/1574888X1130800059

Pak J, Lee JH, Kartolo WA and Lee SH (2016). Cartilage regeneration in human with adipose tissue-derived stem cells: current status in clinical implications. Biomed. Res. Int. 2016: 4702674. http://dx.doi.org/10.1155/2016/4702674

Parker AM and Katz AJ (2006). Adipose-derived stem cells for the regeneration of damaged tissues. Expert Opin. Biol. Ther. 6: 567-578. http://dx.doi.org/10.1517/14712598.6.6.567

Pittenger MF, Mackay AM, Beck SC, Jaiswal RK, et al. (1999). Multilineage potential of adult human mesenchymal stem cells. Science 284: 143-147. http://dx.doi.org/10.1126/science.284.5411.143

Räsänen T and Messner K (1996). Regional variations of indentation stiffness and thickness of normal rabbit knee articular cartilage. J. Biomed. Mater. Res. 31: 519-524. http://dx.doi.org/10.1002/(SICI)1097-4636(199608)31:4<519::AID$\underline{\mathrm{JBM} 12}>3.0 . \mathrm{CO} ; 2-\mathrm{B}$

Singh A, Goel SC, Gupta KK, Kumar M, et al. (2014). The role of stem cells in osteoarthritis: an experimental study in rabbits. Bone Joint Res. 3: 32-37. http://dx.doi.org/10.1302/2046-3758.32.2000187

Tonchev AB, Beltowski J, Fiore M, Rančić G, et al. (2010). Adipobiology of stem cell-based therapy: secretome insight. Biomed. Rev. 21: 57-63. http://dx.doi.org/10.14748/bmr.v21.47

Urt-Filho A, Oliveira RJ, Hermeto LC, Pesarini JR, et al. (2016). Mesenchymal stem cell therapy promotes the improvement and recovery of renal function in a preclinical model. Genet. Mol. Biol. 39: 290-299. PubMed http:// dx.doi.org/10.1590/1678-4685-GMB-2015-0178

Uth K and Trifonov D (2014). Stem cell application for osteoarthritis in the knee joint: a minireview. World J. Stem Cells 6: 629-636. http://dx.doi.org/10.4252/wjsc.v6.i5.629

Genetics and Molecular Research 15 (3): gmr.15038569 
Van Pham P, Bui KH, Ngo DQ, Vu NB, et al. (2013). Activated platelet-rich plasma improves adipose-derived stem cell transplantation efficiency in injured articular cartilage. Stem Cell Res. Ther. 4: 91.http://dx.doi.org/10.1186/scrt277

Vendramin FS, Franco D, Nogueira CM, Pereira MS, et al. (2006). Platelet-rich plasma and growth factors: processing technique and application in plastic surgery. Rev. Col. Bras. Cir. 33: 24-28.

Vilar JM, Morales M, Santana A, Spinella G, et al. (2013). Controlled, blinded force platform analysis of the effect of intraarticular injection of autologous adipose-derived mesenchymal stem cells associated to PRGF-Endoret in osteoarthritic dogs. BMC Vet. Res. 9: 131. http://dx.doi.org/10.1186/1746-6148-9-131

Whitlow J, Shackelford A, Sievert A and Sistino J (2008). Barriers to the acceptance and use of autologous platelet gel. Perfusion 23: 283-289. http://dx.doi.org/10.1177/0267659109104426

Yoshimi T, Kikuchi T, Obara T, Yamaguchi T, et al. (1994). Effects of high-molecular-weight sodium hyaluronate on experimental osteoarthrosis induced by the resection of rabbit anterior cruciate ligament. Clin. Orthop. Relat. Res. 298: 296-304.

Yun S, Ku SK and Kwon YS (2016). Adipose-derived mesenchymal stem cells and platelet-rich plasma synergistically ameliorate the surgical-induced osteoarthritis in beagle dogs. J. Orthop. Surg. Res. 11: 9. http://dx.doi.org/10.1186/ $\underline{\text { s13018-016-0342-9 }}$

Genetics and Molecular Research 15 (3): gmr.15038569 